Scientia Agricola

http://dx.doi.org/10.1590/0103-9016-2014-0137

\title{
Genetic progress after cycles of upland rice recurrent selection
}

Odilon Peixoto de Morais Júnior ${ }^{1}$, Patrícia Guimarães Santos Melo¹, Orlando Peixoto de Morais², Adriano Pereira de Castro², Flávio Breseghello², Marley Marico Utumi ${ }^{2}$, José Almeida Pereira ${ }^{4}$, Flávio Jesus Wruck², José Manoel Colombari Filho²*

${ }^{1}$ Federal University of Goias - Dept. of Genetics and Plant Breeding and Food Engineering - Campus Samambaia, Rod. GO-462, km 0, C.P. 131 - 74001-970 - Goiânia, GO - Brazil.

2Embrapa Rice and Beans, Rod. G0-462, km 12, C.P. 179 75375-000 - Santo Antonio de Goiás, GO - Brazil. ${ }^{3}$ Embrapa Rondonia, Rod. BR-364, km 5.5, C.P. 127 76815-800 - Porto Velho, RO - Brazil.

${ }^{4}$ Embrapa Mid-North - Av. Duque de Caxias, 5650, C.P. 001

- 64006-220 - Teresina, Pl - Brazil.

*Corresponding author <jose.colombari@embrapa.br>

Edited by: Antonio Augusto Franco Garcia

Received April 28, 2014

Accepted December 08, 2014
ABSTRACT: Periodic assessment of the genetic progress made in recurrent selection programs is essential for assessing the evolution of the programs and identifying the main factors that have contributed to this progress. This study aimed to estimate genetic progress in grain yield, plant height and days-to-flowering achieved in the CNA6 population of upland rice (Oryza sativa L.), after four cycles of recurrent selection; and evaluate the genetic potential of this population to generate superior inbred lines after each selection cycle. The experimental data were obtained from progeny yield trials of each recurrent selection cycle. These trials were carried out in two or three locations per cycle, and consisted of $\mathrm{S}_{0: 2}$ progenies and at least three checks. Federer's augmented block design, with one replication on location (the environment), was adopted. Results revealed genetic progress for grain yield and plant height, with total genetic gains of $375.87 \mathrm{~kg} \mathrm{ha}^{-1}$ and $-3.90 \mathrm{~cm}$, respectively, during the four selection cycles. The annual relative gain observed for grain yield was $1.54 \%$. The genetic potential of the population was analysed by the expected proportion of superior inbred lines. The standard adopted as the limit for obtaining superior inbred lines was the average of the checks for each trait. The genetic potential for grain yield and plant height increased during the study period. For days-to-flowering, no genetic gain occurred; however, the genetic potential of the population to generate superior inbred lines for this trait was maintained after the selection cycles.

Keywords: BLUE, BLUP, mixed model, population breeding

Abbreviations: BLUP - Best linear unbiased predictor, BLUE - Best linear unbiased estimator, REML - Restricted maximum likelihood, GY - Grain yield, PH - Plant height

DF - Days-to-flowering, PS - Proportion of superior inbred lines.

\section{Introduction}

In Brazil, upland rice (Oryza sativa L.) occupies more than one million hectares in the savannah region (Pinheiro et al., 2006). In breeding programs, most of the traits of economic importance are quantitative, controlled by many genes and highly influenced by the environment. Thus, one strategy is to concentrate favorable alleles gradually through a recurrent selection method with the intent of maintaining genetic variability and increasing the average value of the population to provide feasible gains in subsequent cycles (Morais, 2005; Hallauer et al., 2010). This method is widely used in outcrossing species, but it is limited to autogamous species, because it is difficult to achieve crossing through recombination of the population in each selection cycle. However, with the discovery of genetic male sterility in rice, the use of the recurrent selection method has become feasible (Fujimaki, 1979).

An important parameter for measuring the success of breeding programs is the monitoring of their efficiency over time by estimating the genetic progress achieved (Hallauer et al., 2010). In irrigated rice, successful results from the efficiency of recurrent selection have been published (Rangel et al., 2002; Rangel et al., 2007), as for other crops, such as common bean (Phaseolus vulgaris L.) (Silva et al., 2010), oats (Avena sativa L.) (Holland et al., 2000), soybean (Glycine $\max$ (L.) (Uphoff et al., 1997) and wheat (Triticum aestivum L.) (Niu et al., 2010). On upland rice, however, few studies have been conducted. Breseghello et al. (2009) estimated that about three times more genetic gains were observed using recurrent selection than pedigree breeding (Soares et al., 1999; Souza et al., 2007).

One of the challenges of breeding programs involves the early evaluation of the potential of a population to generate superior inbred lines. The method of Jinks and Pooni (1976) allows for estimating the potential, given the mean and genetic variance of early generations, with examples in rice (Santos et al., 2002), common bean (Abreu et al., 2002), maize (Toledo and Miranda Filho, 1985), soybean (Toledo, 1987; Triller and Toledo, 1996) and wheat (Snape, 1982).

This study aimed to estimate the genetic progress in grain yield, plant height and days-to-flowering in the CNA6 population of upland rice after four cycles of recurrent selection, and to evaluate the genetic potential of this population to generate superior inbred lines in each cycle.

\section{Materials and Methods}

\section{Genetic material}

The genetic material consisted of $\mathrm{S}_{0: 2}$ progenies of the CNA6 population of upland rice developed by recurrent selection by the Brazilian Agricultural Research Corporation (Embrapa). This population was synthesized in the 1993/94 crop year by incorporating the alleles from 
27 parents into the CNA-IRAT 5/2/1 population (Table 1). The CNA-IRAT 5 population was a product of the partnership between Embrapa and the Institute for Research in Tropical Agriculture (IRAT) in France, currently known as the French Center for International Cooperation in Development-oriented Agricultural Research (CIRAD). This population was synthesized in 1984 by intercrossing 26 lines of the subspecies japonica and one line of indica originated from the mutation of IR 36 bred by Singh and Ikehashi (1981). This mutant possesses the recessive gene that affects genetic male sterility, which makes possible the recombination of progenies (Fujimaki, 1979).

The CNA6 population was initially subjected to two cycles of mass selection in $\mathrm{S}_{0}$ generation followed by recombination. The sample size used in these cycles was highly conservative (about 100 individual plants) to minimize the occurrence of genetic drift. These two cycles occured in the 1994/95 and 1995/96 crop years in order

Table 1 - Percentages of participation of each parent in the CNA6 population of upland rice.

\begin{tabular}{lc}
\hline Parents & $(\%)$ \\
\hline CNA-IRAT 5/2/1 & 62.60 \\
IAC 25R & 3.47 \\
IRAT 112R & 3.47 \\
Bico Ganga (CNA 0420) & 1.93 \\
Precoce Branco (780029) & 1.93 \\
Muruim Ligeiro (780299) & 0.56 \\
IAC 84-198 & 0.55 \\
Três Meses Branco (780353) & 1.93 \\
Rio Verde & 1.93 \\
Guaíra (CNA 1240) & 1.93 \\
Campininho (780191) & 1.93 \\
Arroz de Revenda (CNA 5584) & 1.93 \\
Japonês Claro (780169) & 1.93 \\
No 392 Gervex & 1.68 \\
CNA 6710 & 1.38 \\
Puteca-GO (780217) & 1.38 \\
Rio Paraguai & 1.38 \\
IREM 238 (IREM 293-B) & 0.83 \\
Agulha Branco (CNA 6524) & 0.61 \\
Japonês (780135) & 0.61 \\
Cem Dias (780177) & 0.56 \\
Cana Roxa Ligeiro (780279) & 0.56 \\
Pratão Goiano (780336) & 0.56 \\
Vermelho (790044) & 0.56 \\
Cuttack 4 & 0.55 \\
RikutoNorin & 0.56 \\
IRAT 10 & 0.55 \\
CNA 6186 & 0.55 \\
\hline The CNA-RAT 5/2/1 poplaton was & 50 cycs \\
\hline
\end{tabular}

aThe CNA-IRAT 5/2/1 population was submitted to two selection cycles for grain quality and one recombination cycle. Recombination was done using seeds with $25 \%$ of male sterility from $\mathrm{S}_{\text {g }}$ generation; 'bulk of lines with rice blast resistance (Magnaporthe grisea) with genes from following accessions: BG90-2, Três Marias, Pusur, Dawn, Basmati 370, H-5, Colombia 1 and Ramtulasi; 'Bulk of lines with rice blast resistance ( $M$. grisea) with genes from following accessions: T-23, CTG 1516, C 46-15, Carreon and Tetep. to standardize the maturity cycle and eliminate genotypes with excessive plant height. In the 1997/98 crop year, the first evaluation for grain yield was carried out based on $\mathrm{S}_{0: 1}$ progenies. The remaining seeds from the selected progenies were recombined in the 1998/99 crop year in a synthesis of the population of the third cycle.

After this cycle was complete, the population was subjected to four more selection cycles, each taking three years, comprising the following steps: selection of individual plants within each crossing in $\mathrm{S}_{0}$ generation in the first year; observation and selection of the best $\mathrm{S}_{0: 1}$ progenies (harvested in bulk) and selection of the top five panicles from fertile plants $\left(S_{1: 2}\right.$ progenies $)$ within each selected $\mathrm{S}_{0: 1}$ progeny to be used as units of recombination in the second year; evaluation and selection of $\mathrm{S}_{0: 2}$ progenies in yield trials in different locations; and field recombination of the selected progenies with the use of the genetic male sterility in $\frac{1}{6}$ of the seeds from $S_{1: 2}$ progenies (msms genotype) in the third year (Figure 1).

Individual plants were selected based on plant architecture, disease resistance and dimensions of the grain (long and thin), and the quality requirements of the Brazilian consumer market. The selection of $S_{0: 1}$ progenies focused on traits of high heritability, including plant height, days-to-flowering, lodging resistance, disease resistance (mainly to blast caused by Magnaphorte grisea) and grain quality. The selection of $\mathrm{S}_{0: 2}$ progenies from yield trials, in different locations, prioritized the grain yield trait, which is quantitative, and highly influenced by environmental conditions. These target traits for the upland rice breeding program in Brazil are better described in Breseghello et al. (2011) and Colombari Filho et al. (2013).

\section{Experimental data}

This study used data on trait grain yield (GY, kg $\left.\mathrm{ha}^{-1}\right)$, plant height $(\mathrm{PH}, \mathrm{cm})$ and days-to-flowering (DF, days) collected from yield trials of $\mathrm{S}_{0: 2}$ progenies. The trials were conducted during the 2000/01,2003/04, 2006/07 and 2009/10 crop years, which corresponded to cycles 1 , 2, 3 and 4, respectively. For each cycle, the trials were carried out in different locations (Table 2).

The data set was unbalanced because in each cycle, the trials consisted of $\mathrm{S}_{0: 2}$ progenies from the respective cycle with at least three checks. As check cultivars (commercial) change over time, a number of checks were substituted across the cycles; however, at least two common check cultivars were maintained between cycles (Table 2).

Federer's augmented block design with one replication within the location (the environment) was used (Federer, 1956). Plots consisted of four 5-m-long rows, spaced $0.30 \mathrm{~m}$, with sixty seeds per meter sowed either manually or by machine. To evaluate GY, two central rows were harvested, and the first and last $0.50 \mathrm{~m}$ of each row were not used. For $\mathrm{PH}$, an average of three readings for the distance from the base of the plant to the end of the panicle was recorded. For DF, the interval between 


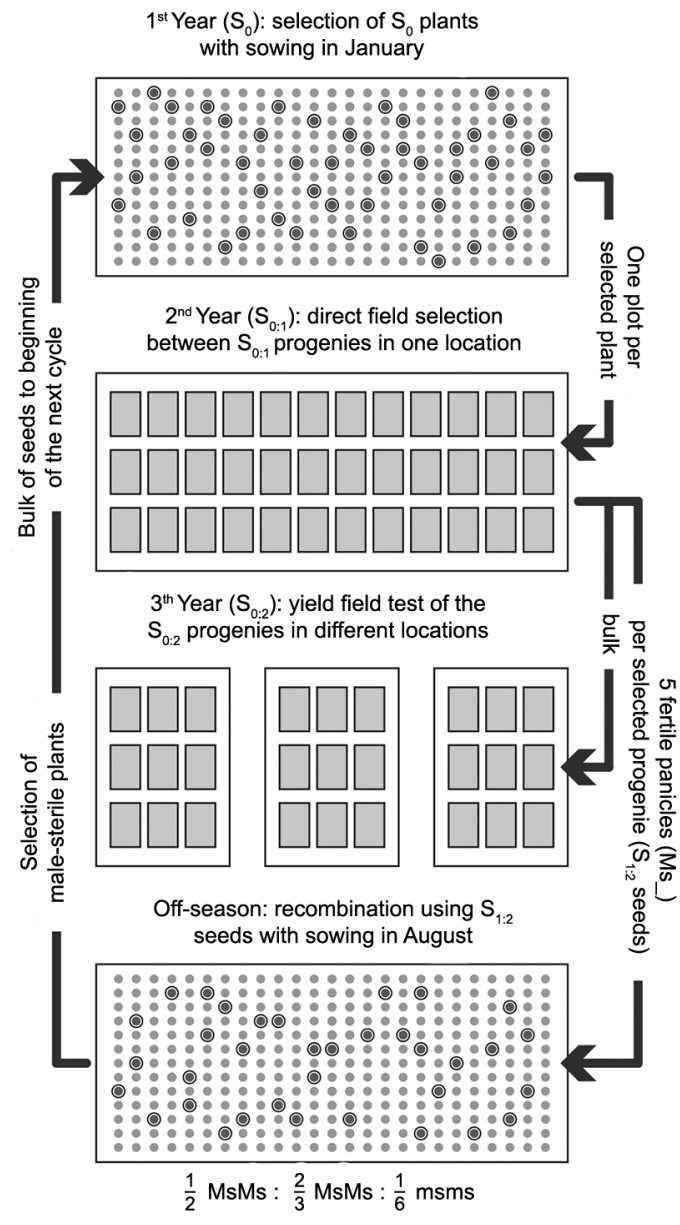

\begin{tabular}{|c|c|c|}
\hline Year* $^{*}$ & Step & Population* * \\
\hline 1993/94 & Synthesis & CNA6 \\
\hline Nov/1994 & $\mathrm{S}_{0}$ & CNA6 \\
\hline May/1995 & $\operatorname{Rec}$ & CNA6/1/1 \\
\hline Nov/1995 & $\mathrm{S}_{0}$ & $\ldots$ \\
\hline May/1996 & $\operatorname{Rec}$ & CNA6/2/1 \\
\hline $1996 / 97$ & $\mathrm{~S}_{0}$ & $\ldots$ \\
\hline 1997/98 & $S_{0: 1}$ & $\ldots$ \\
\hline Aug/1998 & $\operatorname{Rec}$ & CNA6/3/1 \\
\hline Jan/1999 & $\mathrm{S}_{0}$ & $\ldots$ \\
\hline 1999/00 & $\mathrm{S}_{0: 1}$ & $\ldots$ \\
\hline $2000 / 01$ & $\mathrm{~S}_{0: 2}$ & $\ldots$ \\
\hline Aug/2001 & $\operatorname{Rec}$ & CNA6/4/1 \\
\hline Jan/2002 & $\mathrm{S}_{0}$ & $\ldots$ \\
\hline $2002 / 03$ & $S_{0: 1}$ & $\ldots$ \\
\hline $2003 / 04$ & $\mathrm{~S}_{0: 2}$ & $\ldots$ \\
\hline Aug/2004 & $\operatorname{Rec}$ & CNA6/5/1 \\
\hline Jan/2005 & $\mathrm{S}_{0}$ & $\ldots$ \\
\hline $2005 / 06$ & $\mathrm{~S}_{0: 1}$ & $\ldots$ \\
\hline $2006 / 07$ & $S_{0: 2}$ & $\ldots$ \\
\hline Aug/2007 & $\operatorname{Rec}$ & CNA6/6/1 \\
\hline Jan/2008 & $\mathrm{S}_{0}$ & $\ldots$ \\
\hline $2008 / 09$ & $S_{0: 1}$ & $\ldots$ \\
\hline $2009 / 10$ & $\mathrm{~S}_{0: 2}$ & $\ldots$ \\
\hline
\end{tabular}

${ }^{*}$ Crop year, or Month and Year of sowing; and ${ }^{*}{ }^{*} \mathrm{CNA6} / \mathrm{C} / \mathrm{R}$, where $\mathrm{C}$ is the number of the selection cycle and $\mathrm{R}$ is of the number recombination to start the next cycle.

Figure 1 - Scheme of recurrent selection using male sterility gene (msms) and schedule of development of the CNA6 population of upland rice in recurrent selection program.

sowing and heading of $50 \%$ of the plants was evaluated. The yield trials of $\mathrm{S}_{0 \cdot 2}$ progenies were performed similarly to those in commercial production; however, fungal diseases were not chemically controlled to allow for selection of progenies with genetic resistance.

\section{Statistical analyses}

Statistical analysis was performed based on the mixed linear model $\mathrm{y}_{i j k m}=\mu+\mathrm{l}_{k}+\mathrm{b}_{j / k}+\mathrm{t}_{m}+\mathrm{g}_{\mathrm{i} / \mathrm{m}}+\mathrm{gl}_{i k}$ $+\varepsilon_{i j k m^{\prime}}$ where: $y_{i j k m}$ is the observation of genotype $\mathrm{i}$ in block $\mathrm{j}$ in environment $\mathrm{k}$ belonging to type $\mathrm{m}, \mu$ the overall mean, $l_{k}$ the fixed effect of environment $\mathrm{k}(\mathrm{k}=1,2$, $\ldots, \mathrm{K}), \mathrm{b}_{j / k}$ the fixed effect of block $\mathrm{j}$ within environment $\mathrm{k}(\mathrm{j}=1,2, \ldots, \mathrm{J}), \mathrm{t}_{m}$ the fixed effect of type $\mathrm{m}(\mathrm{M}=5)$, with four groups of progenies and one group of checks), $\mathrm{g}_{i / m}$ the random effect of genotype $\mathrm{i}$ within type $\mathrm{m}(\mathrm{i}=1$, $\left.2, \ldots, \mathrm{P}_{m^{\prime}} \mathrm{P}_{m}+1, \mathrm{P}_{m}+2, \mathrm{P}_{m}+\mathrm{C}\right)$, where $\mathrm{P}_{m}$ is the number of progenies within cycle $\mathrm{m}, \mathrm{m}=1,2, \ldots, 4$, and $\mathrm{C}$ the number of checks) assuming $g_{i / m} \sim \operatorname{NID}\left(0, \sigma_{g}^{2}\right) \cdot \mathrm{gl}_{i k}$ is the random effect of the genotype-environment interaction assuming $\mathrm{gl}_{i k} \sim \operatorname{NID}\left(0, \sigma_{g l}^{2}\right)$, and $\varepsilon_{i j k m}$ the random effect of the experimental error associated with the ijk-th plot, assuming NID $\left(0, \sigma^{2}\right)$ (Duarte et al., 2001).

Locations and years (cycles) were treated as environments for the following reasons: (i) only two cycles with two locations were common to all periods (Table 2) and (ii) there was no intention to analyze the effect of the interactions between genotype and environment partitioned into locations and years (cycles).

To obtain the relationship between traits in the four cycles of recurrent selection were calculated the genetic $\left(\mathrm{r}_{G}\right)$, phenotypic $\left(\mathrm{r}_{F}\right)$ and environment $\left(\mathrm{r}_{E}\right)$ coefficients of correlation were calculated. The estimate of correlation coefficient $\left(\hat{r}_{x, y}\right)$ was based on the ratio of the estimate of the covariance of $x$ and $y\left(\operatorname{Cov}_{(x, y)}\right)$ to the estimates of standard deviation of the two traits $\left(\sigma_{x}\right.$ and $\left.\sigma_{y}\right)$, i.e.,

$\hat{r}_{x, y}=\frac{\operatorname{Cov}_{(x, y)}}{\sigma_{x} \sigma_{y}}$

(Steel and Torrie, 1960), where $\mathrm{x}$ and y refer to pairs of traits. For testing the significance of correlation coefficients, the t-test was applied. 
Table 2 - Locations, cultivars used as checks and number of $\mathrm{S}_{0: 2}$ progenies of the CNA6 population, that comprised the yield trials of each recurrent selection cycle.

\begin{tabular}{|c|c|c|c|c|}
\hline Descriptions & Cycle 1 & Cycle 2 & Cycle 3 & Cycle 4 \\
\hline \multicolumn{5}{|l|}{ Locations } \\
\hline 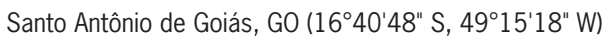 & 1 & 1 & 1 & 1 \\
\hline Primavera do Leste, MT (153' $\left.35^{\prime \prime} \mathrm{S}, 54^{\circ} 17^{\prime} 50^{\prime \prime} \mathrm{W}\right)$ & 1 & & & \\
\hline 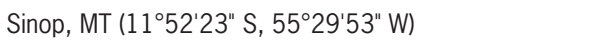 & & 1 & & 1 \\
\hline Vilhena, RO (1244' $\left.03^{\prime \prime} \mathrm{S}, 60^{\circ} 08^{\prime} 40^{\prime \prime} \mathrm{W}\right)$ & 1 & & & \\
\hline Teresina, PI $\left(05^{\circ} 05^{\prime} 21^{\prime \prime} \mathrm{S}, 42^{\circ} 48^{\prime} 06^{\prime \prime} \mathrm{W}\right)$ & & & 1 & \\
\hline Paragominas, PA (0259'51" S, 47²1'12" W) & & & & 1 \\
\hline \multicolumn{5}{|l|}{ Checks } \\
\hline BRS Primavera & 1 & 1 & 1 & 1 \\
\hline Guarani & 1 & 1 & 1 & \\
\hline Carajás & 1 & 1 & 1 & \\
\hline BRS Bonança & & 1 & 1 & 1 \\
\hline BRSMG Curinga & & & & 1 \\
\hline BRS Sertaneja & & & & 1 \\
\hline $\mathrm{S}_{0: 2}$ Progenies & 220 & 92 & 114 & 61 \\
\hline
\end{tabular}

The mixed linear model adopted in its matrix form was represented by the generalized linear mixed model $\mathrm{y}=\mathrm{X} \beta+\mathrm{Z} \lambda+\varepsilon$, where $\mathrm{y}$ is the vector of the observed means, $\mathrm{X}$ and $\mathrm{Z}$ are the respective incidence matrices of the fixed and random effects, $\beta$ and $\lambda$ are vectors of the fixed and random effects, respectively, and $\varepsilon$ is the vector of random errors (Henderson, 1959). The matrix equation was calculated by restricted maximum likelihood (REML) to obtain the best linear unbiased estimate (BLUEs) of the fixed effect of type $\mathrm{m}$ (four groups of $\mathrm{S}_{0: 2}$ progenies and one group of checks) with the corresponding covariance matrices and the best linear unbiased prediction (BLUPs) of the random effect of the genotypes ( $\mathrm{S}_{0: 2}$ progenies).

Analyses of the average weighted genetic gain were implemented according to the method of adjusted means described by Breseghello et al. (1998). In the adapted version, the common treatments between different cycles were used as checks. The average genetic gain and the associated genetic covariance matrix were calculated for four cycles using generalized linear regression for the BLUE averages of the type (i.e., the four groups of $\mathrm{S}_{0: 2}$ progenies) in accordance with the equations

$\hat{\beta}=\left(X^{\prime} V^{-1} X\right)^{-1}\left(X^{\prime} V^{-1} Y\right)=\left[\frac{\hat{b}_{o}}{\hat{b}_{1}}\right]$, and $\hat{V}(\hat{\beta})=\left(X^{\prime} V^{-1} X\right)^{-1}$,

where: $\beta$ is the vector of the generalized linear regression solutions, $\mathrm{X}$ is the incidence matrix formed by a row of 1 's and one column indicating the type in the series of progeny groups, $\mathrm{V}$ is the covariance matrix of the BLUEs of the type, $\mathrm{Y}$ is the vector of the BLUEs of the type (i.e., the four groups of progenies), $\hat{V}(\hat{\beta})$ the covariance matrix of $\hat{\beta}, b_{o}$ the estimate of the intercept and $\hat{b}_{1}$ the estimate of the slope. For the significance of the slope $\left(b_{1}\right)$ a t-test was applied. Details on the method by which $\hat{V}(\hat{\beta})$ was determined were presented by Breseghello et al. (1998).
The relative mean genetic gain (G) per cycle was estimated as the ratio of the estimated angular regression coefficient $\left(\hat{b}_{1}\right)$ to the mean value estimated for cycle $1\left(\hat{y}_{1}\right)$ as a percentage according to the equation

$G \%=\left(\frac{\hat{b}_{1}}{\hat{y}_{1}}\right) 100$.

To obtain the genetic gain given from the cumulative gains, the equation

$G_{A} \%=\left[\left(\frac{\hat{b}_{1}}{\hat{y}_{1}}+1\right)^{(1 / y)}-1\right] 100$

was used to estimate the annual relative $G\left(G_{A}\right)$, where $y$ corresponds to the number of years in each cycle. To estimate the total relative $\mathrm{G}\left(\mathrm{G}_{T}\right)$ of the four cycles of recurrent selection, given the cumulative gains, the equation

$G_{T} \%=\left[\left(\frac{\hat{b}_{1}}{\hat{y}_{1}}+1\right)^{c-1}-1\right] 100$

was adopted, where c corresponds to the number of selection cycles in the period during which the genetic progress was estimated.

To obtain the weighted coefficient of determination using the method of Breseghello et al. (1998), the general equation of the sum of the squares from the hypothesis of linear models was adopted (Searle, 1971) for each component of variation, as described by Pereira et al. (2008). The gains between cycles were also estimated by generalized linear regression analysis and by contrasting the observed mean values for each cycle and the total gain and mean values of the first and last cycles estimated by the method of adjusted means described by Breseghello et al. (1998). For the significance of each gain, the t-test was applied. 
The proportion of superior inbred lines (PS) of the population in each cycle was obtained from the method described by Toledo (1987), from the procedure described by Jinks and Pooni (1976), which estimates the probability of a population to generate lines that exceed a certain standard in generation $\mathrm{F}_{\infty}$. This probability corresponds to the area to the right or left of a given value on the abscissa of the normal distribution. To determine this area considering the standard normal distribution, the ordinate $\mathrm{Z}$ was estimated by the equation

$Z=\frac{\bar{C}-\bar{P}}{\left(2 \hat{\sigma}_{A}^{2}\right)^{\frac{1}{2}}}$

where $\mathrm{Z}$ is the value of the abscissa of the standard normal distribution $\mathrm{Z}(0,1), \bar{C}$ is the standard adopted as the limit for obtaining superior inbred lines (in the present study, the average of the checks for each trait was considered), $\bar{P}$ is the average of the $\mathrm{S}_{0: 2}$ progenies and is considered equal to the average of the population after reaching homozygosity, and $\hat{\sigma}_{A}^{2}$ is the estimate of the additive genetic variance of $\mathrm{S}_{0: 2}$ progenies. The value of $\hat{\sigma}_{A}^{2}$ was obtained by assuming that the estimate genetic variance among $S_{0: 2}$ progeny $\left(\hat{\sigma}_{p}^{2}\right)$ is equivalent to generation $\mathrm{F}_{2: 4}$, i.e.,

$\hat{\sigma}_{A}^{2}+\frac{1}{16} \hat{\sigma}_{D}^{2}$

(Cockerham, 1963), and $\sigma_{p}^{2}$ estimated by REML (Searle et al., 1992).

To calculate PS, two assumptions for the average degree of dominance (add) were considered according to the equation add $=\left(2 \hat{\sigma}_{D}^{2} / \hat{\sigma}_{A}^{2}\right)^{\frac{1}{2}}:(\mathrm{i})$ add $=0$, with the estimate of $\hat{\sigma}_{A}^{2}$ considered equal to the estimate of the genetic variance among $\mathrm{S}_{0: 2}$ progenies, $\left(\hat{\sigma}_{p}^{2}\right)$, i.e., $\hat{\sigma}_{A}^{2} \cong \hat{\sigma}_{p i}^{2}$ (ii) add $=1$, with the genetic variance of dominance $\left(\hat{\sigma}_{D}^{2}\right)$ equal to $\left(\frac{1}{2}\right)$ of $\hat{\sigma}_{A}^{2}$. Thus, the estimate of $\hat{\sigma}_{A}^{2}$ equals $\left(\frac{16}{17}\right)$ of the estimate of $\hat{\sigma}_{p}^{2}$, i.e., $\hat{\sigma}_{A}^{2} \cong\left(\frac{16}{17}\right) \hat{\sigma}_{p}^{2}($ Cockerham, 1963). It is important to consider that because this population was derived from recurrent selection, it is most likely not in Hardy-Weinberg equilibrium and allele frequency is different by 0.50 . Furthermore, in addition to the additive genetic variance and dominance, other variance components were considered null for the purpose of estimating PS values (Cockerham, 1983).

All statistical analyses were performed using the glm, varcomp, mixed and iml procedures of the SAS (Statistical Analysis System, version 9.2).

\section{Results and Discussion}

Average GY values were lower in progenies than in the checks in all cycles of recurrent selection (Figure 2). The average is an important parameter in population breeding because a low average indicates that a longer period is required to achieve the desired level of progress (Hallauer et al., 2010). Lower average values were found in the progenies of the CNA6 population than in
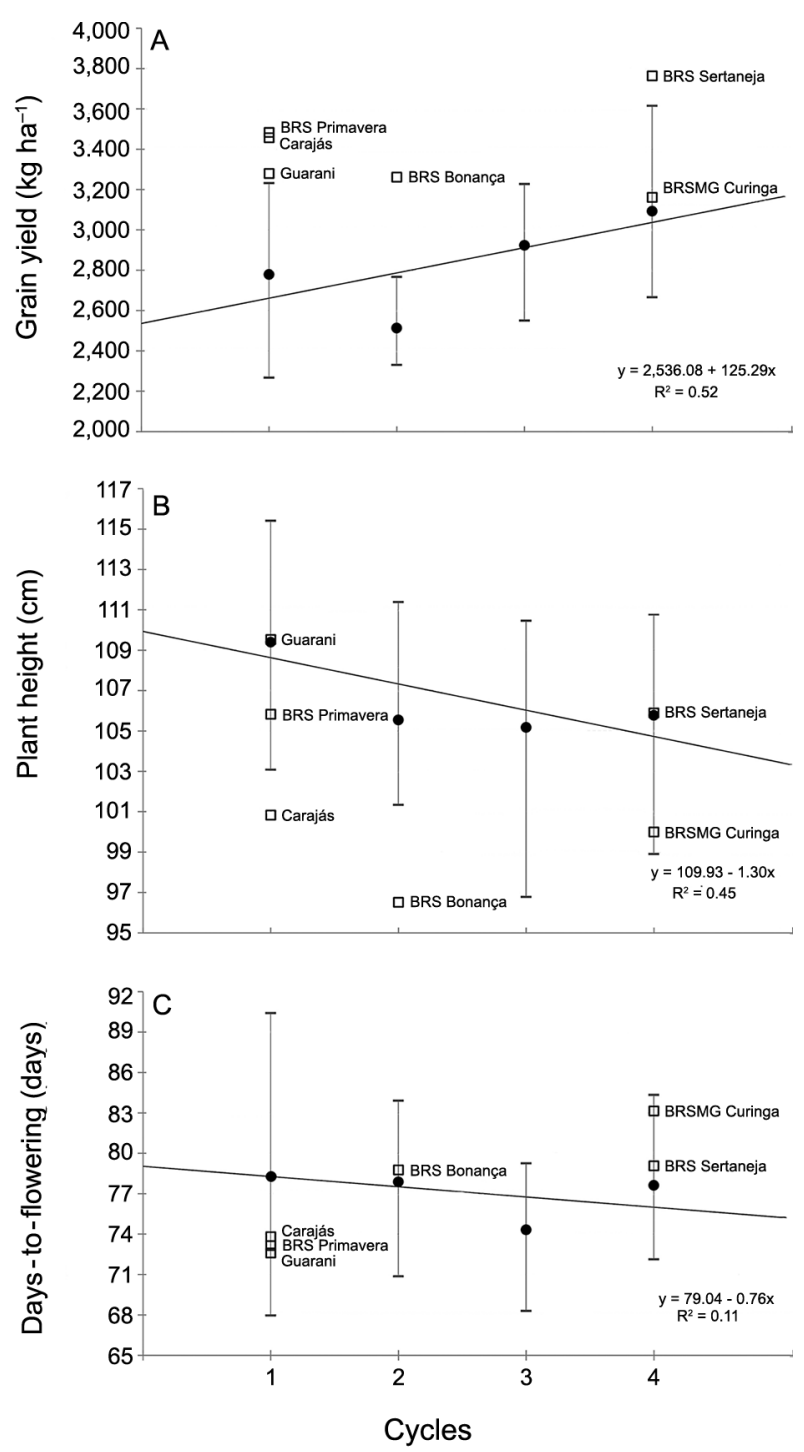

Figure 2 - Genetic progress over four cycles of upland rice recurrent selection of the CNA6 population, for grain yield (A), plant height (B) and days-to-flowering (C). Where: black spot refers to the $\mathrm{S}_{0: 2}$ progeny means (BLUE) in each cycle, together with the amplitude of the $S_{0: 2}$ progeny means (BLUPs of the highest and lowest mean of the progenies); White square refers to the check mean (BLUP) positioned in the cycle that was first tested; and generalised linear regression adjusted, for the $S_{0: 2}$ progeny means (BLUE) during the four cycles.

the checks. According to Rangel et al. (2002), this may be due to the presence of the gene for genetic male sterility in the progenies and the reduced number of selection cycles.

There was average reduction in GY in the $\mathrm{S}_{0: 2}$ progenies (BLUE) and the range of variation of mean values (BLUPs) in cycle 2 (Figure 2). This reduction might have occurred because there was strong selection pressure for traits such as modern plant architecture, grain di- 
mensions (long and thin) and lodging resistance in the previous generation $\left(\mathrm{S}_{0.1}\right.$ progenies). The gains observed in the $S_{0.2}$ progenies also resulted from gains achieved in the selection of traits with high heritability in previous generations for the same cycle $\left(\mathrm{S}_{0}\right.$ and $\left.\mathrm{S}_{0: 1}\right)$. In cycle 3 , after recombination, the average BLUE returned to a level similar to that observed in cycle 1 ; however, the amplitude of the variation in BLUPs remained lower in the subsequent cycles than in cycle 1 , with the beginnings of restoration in cycle 4 .

The reduction in amplitude of the BLUP for GY most likely occurred due to the strong selection pressure applied during cycle $2\left(\mathrm{~S}_{0: 1}\right.$ progenies $)$, the effects of which appeared in the subsequent cycle. After cycle 2, clear genetic progress in GY attributable to the increase in the average $\mathrm{GY}$ of the $\mathrm{S}_{0: 2}$ progenies was observed (Figure 2).

The results of the generalized linear regression adjusted for the average values of the $\mathrm{S}_{0: 2}$ progenies (BLUE) in the four cycles suggest that linear genetic progress in GY $(p<0.05)$ occurred during the cycles of recurrent selection (Figure 2 and Table 3). The average gain per cycle was $125.29 \mathrm{~kg} \mathrm{ha}^{-1}$, which corresponded to a gain of $4.71 \%$ per cycle. It should be emphasized that the information on relative gains for specific phases cannot be obtained by simple operations that consider only the number of phases and the intervals between them, because the gains are cumulatives (i.e., compounds). Thus, the annual and total relative gains were also estimated and found to be equal to $1.54 \%$ and $14.80 \%$, respectively, of the initial average (Table 3).

Estimates of genetic gains in GY in rice recurrent selection programs have been reported; however, the methods employed in these studies are generally different, which makes comparisons difficult. In studies that used similar methods, such as that of Breseghello et al. (2009), an annual genetic gain of $3.60 \%$ was estimated in the CG3 population of upland rice after three cycles

Table 3 - Estimates of linear regression parameters, with first cycle mean $\left(\hat{Y}_{1}\right)$, angular coefficient $\left(\hat{b}_{1}\right)$, standard deviation (SD), coefficient of experimental variation (CV \%) and respective annual average genetic gains $\left(G_{A} \%\right)$, per cycle $(G \%)$ and total $\left(G_{T} \%\right)$, for grain yield (GY, $\left.\mathrm{kg} \mathrm{ha}^{-1}\right)$, plant height $(\mathrm{PH}, \mathrm{cm})$ and days-toflowering (DF, days).

\begin{tabular}{lccc}
\hline \multirow{2}{*}{ Parameters } & \multicolumn{3}{c}{ Traits } \\
\cline { 2 - 4 } & $\mathrm{GY}$ & $\mathrm{PH}$ & $\mathrm{DF}$ \\
\hline$\hat{Y}_{1}, 661.37$ & 108.63 & 78.27 \\
$\hat{b}_{1}$ (gain per cycle) & $125.29^{*}$ & $-1.30^{\text {ns }}$ & $-0.77^{\text {ns }}$ \\
$\mathrm{SD}$ & 75.85 & 91.86 & 66.55 \\
$t$ value & 1.65 & -1.41 & -1.15 \\
$p$ value $\left(\mathrm{H}_{\mathrm{o}}: b_{1}=0\right)$ & 0.050 & 0.079 & 0.124 \\
$\mathrm{CV} \%$ & 16.31 & 4.95 & 1.01 \\
\hline $\mathrm{G}_{\mathrm{A}} \%$ & 1.54 & -0.40 & -0.33 \\
$\mathrm{G} \%$ (3 years) & 4.71 & -1.20 & -0.98 \\
$\mathrm{G}_{\mathrm{T}} \%$ (9 years) & 14.80 & -3.55 & -2.92 \\
\hline
\end{tabular}

${ }^{\text {nsand }}{ }^{*}$ not significant and significant at $5 \%$ level by t-test, respectively. of recurrent selection. Rangel et al. (2002) estimated an average genetic gain of $1.56 \%$ in the CNA-IRAT 4 population of irrigated rice subjected to three cycles of recurrent selection, a result similar to that observed in this study. When gains between cycles were compared, gains $(p<0.05)$ of $410.10 \mathrm{~kg} \mathrm{ha}^{-1}$ between cycles 2 and 3 and of $375.87 \mathrm{~kg} \mathrm{ha}^{-1}$ between the first and last cycle $(p<0.05)$ were detected, considered satisfactory for the period (Table 4).

The average $\mathrm{PH}$ of the $\mathrm{S}_{0: 2}$ progenies (BLUE) was higher than the overall average $\mathrm{PH}$ of checks in all selection cycles but similar to the average PH of the Guarani check in cycle 1 and the average PH of the BRS Sertaneja check in the last cycle. After the strong selection pressure in cycle 2 to reduce the plant height, the BLUEs remained constant and the amplitudes of variation returned to baseline levels (Figure 2).

According to the generalized linear regression analysis adjusted for the averages of $\mathrm{S}_{0: 2}$ progenies (BLUE), no genetic gain $(p>0.05)$ in $\mathrm{PH}$ was observed (Figure 2 and Table 3). Breseghello et al. (2009) also observed no genetic gain $(p>0.05)$ in $\mathrm{PH}$ in upland rice. However, when comparing the gains between cycles, a total gain of $-3.90 \mathrm{~cm}$ was detected $(p<0.05)$ (Table 4$)$. The low gains in $\mathrm{PH}$ may have resulted from the use of genetic male sterility, controlled by a recessive gene $(m s)$, in the recombination, because the taller male fertile plants are favored by better dispersion of pollen grains than shorter male fertile plants. Thus, a rouging of the tallest plants during the recombination of each cycle of the CNA6 population is recommended.

The average DF was higher in $\mathrm{S}_{0: 2}$ progenies (BLUE) than in the checks only in cycle 1 , with similar magnitudes in the other cycles (Figure 2). In cycle 3, a marked reduction was observed in the average $\mathrm{DF}$ of $\mathrm{S}_{0.2}$ progenies, possibly due to the strong selection for earliness in the previous generation $\left(\mathrm{S}_{0: 1}\right.$ progenies $)$. However, in cycle 4 , the average BLUE of the $S_{0: 2}$ progenies re-

Table 4 - Estimates of genetic gains between cycles, first-second cycle (G12), second-third cycle (G23), third-fourth cycle (G34) and first-fourth (G14), with the respective standard deviations (SD), for grain yield (GY, $\left.\mathrm{kg} \mathrm{ha}^{-1}\right)$, plant height $(\mathrm{PH}, \mathrm{cm})$ and days-toflowering (DF, days).

\begin{tabular}{lccccc}
\hline Traits & Descriptions & Genetic gain & SD & t value & p value \\
\hline \multirow{4}{*}{ GY } & G12 & $-265.66^{\text {ns }}$ & 238.74 & -1.11 & 0.133 \\
& G23 & $410.10^{*}$ & 244.17 & 1.68 & 0.046 \\
& G34 & $169.07^{\text {ns }}$ & 250.45 & 0.68 & 0.250 \\
& G14 (total) & $375.87^{*}$ & 206.63 & 1.82 & 0.035 \\
\hline \multirow{4}{*}{ PH } & G12 & $-3.91^{\text {ns }}$ & 2.72 & -1.44 & 0.076 \\
& G23 & $-0.44^{\text {ns }}$ & 2.78 & -0.16 & 0.437 \\
& G34 & $0.65^{\text {ns }}$ & 2.92 & 0.22 & 0.412 \\
& G14 (total) & $-3.90^{*}$ & 2.30 & -1.69 & 0.046 \\
\hline \multirow{4}{*}{ DF } & G12 & $-0.40^{\text {ns }}$ & 1.90 & -0.21 & 0.417 \\
& G23 & $-3.55^{*}$ & 1.75 & -2.03 & 0.021 \\
& G34 & $3.30^{*}$ & 1.96 & 1.69 & 0.046 \\
& G14 (total) & $-2.31^{\text {ns }}$ & 1.81 & -1.27 & 0.102 \\
\hline ns and *not significant and significant at 5 \% level by t-test, respectively.
\end{tabular}


turned to the levels observed in cycle 2 . The restoration of the average DF in cycle 4 may have occurred because male sterile plants occurred with a frequency of $\frac{1}{6}$ during the recombination phase and because earliness was not favored in field recombination.

Taking the linear regression analysis into account, no genetic gains $(p>0.05)$ in DF were detected (Figure 2 and Table 3$)$. However, a reduction of 3.55 days $(p<$ $0.05)$ was detected between cycles 2 and 3 and an increase of 3.30 days was detected between cycles 3 and 4 (Table 4). Between cycles 1 and 2, no selection for DF was performed, which explains the absence of genetic gain. The oscillations in gains between cycles and the coefficient of determination of only $11 \%$ explain the absence of detected total gain in DF (Figure 2). The use of alternative selection criteria, such as the selection index, might have contributed to simultaneous gains in the different traits (Smith et al., 1981; Berilli et al., 2013).

The estimates of genetic correlation coefficients corroborate results from genetic gains observed for the three traits (Table 5). The genetic correlation between GY and $\mathrm{PH}$ was negative $\left(\widehat{r_{G}}=-0.42\right)$ and significant $(p \leq 0.01)$, which was similar to the results verified by Breseghello et al. (2011). No genetic correlation was detected between GY and DF $\left(\widehat{r_{G}}=-0.01\right)$ and a weak negative genetic correlation $\left(\widehat{r_{G}}=-0.11, p \leq 0.01\right)$ was verified between $\mathrm{PH}$ and DF. Thus, these estimates of genetic correlation explain the possibility of obtaining genetic progress simultaneously for increasing grain yield and reducing plant height, but with some difficulty for earliness, because the progenies with lower plant height tend to have a longer cycle in the CNA6 population.

Based on estimates of the expected proportion of superior inbred lines (PS) as a function of the average values of checks in each selection cycle calculated for traits GY, PH and DF (Table 6), there were no differences $(p>0.05)$ in PS between two assumptions considered (average degree of dominance, add, equal to zero or 1). Thus, the dominance variance $\left(\sigma_{D}^{2}\right)$ was confirmed as having a negligible influence compared to the additive variance $\left(\sigma_{A}^{2}\right)$. This result corroborated with Santos et al. (2002), who similarly argued that the dominance variance had a minimal impact on trait because the magnitude of the coefficient associated with this parameter was low, i.e., equal to $\frac{1}{16} \sigma_{D}^{2}$ (Cockerham, 1963).

Among the cycles, there was considerable variation in PS in traits under the two assumptions. Differences $(p<0.05)$ in PS between cycles were found for GY, being strongly reduced in cycle 2 (with an estimate of zero), doubled in cycle 3 and 4.5 times higher in cycle 4 than in the first cycle. For $\mathrm{PH}$, the largest PS values were detected in cycles 2 and 3, with values approximately three times higher than those observed in the first cycle. For DF, the PS remained constant in all cycles except cycle 3, where the estimate was twice as high as that of the first cycle, mainly due to the strong selection for earliness in the $\mathrm{S}_{0: 1}$ progenies in cycle 3.
Table 5 - Estimates of genetic correlation coefficient (above the diagonal), environment correlation (in parenthesis) and phenotypic correlation (below the diagonal) between grain yield (GY, $\mathrm{kg} \mathrm{ha}^{-1}$ ), plant height $(\mathrm{PH}, \mathrm{cm})$ and days-to-flowering (DF, days), obtained from $\mathrm{S}_{0: 2}$ progenies during the four cycles of recurrent selection.

\begin{tabular}{lccc}
\hline Traits & GY & PH & DF \\
\hline \multirow{2}{*}{ GY } & 1.00 & $-0.42^{* *}$ & $-0.01^{\text {ns }}$ \\
& & $(0.33)^{* *}$ & $(0.00)^{\text {ns }}$ \\
\hline PH & $0.11^{*}$ & 1.00 & $-0.11^{\text {** }}$ \\
& & & $(0.06)^{\text {ns }}$ \\
\hline DF & $-0.01^{\text {ns }}$ & $-0.03^{\text {ns }}$ & 1.00 \\
\hline ns, * and ** not significant, significant at 5 and $1 \%$ levels by t-test, respectively.
\end{tabular}

Table 6 - Estimates of the proportion of superior inbred lines (PS) that are expected from each cycle of recurrent selection, considering two suppositions: average degree of dominance (add) equal to zero [PS (add=0)] and add equal to 1 [PS (add=1)], for grain yield (GY, $\mathrm{kg} \mathrm{ha}^{-1}$ ), plant height $(\mathrm{PH}, \mathrm{cm})$ and days-toflowering (DF, days).

\begin{tabular}{lccccc}
\hline Traits $^{\ddagger}$ & Parameters & Cycle 1 & Cycle 2 & Cycle 3 & Cycle 4 \\
\hline \multirow{2}{*}{ GY } & $[$ PS (add $=0)]$ & 0.064 & 0.000 & 0.118 & 0.286 \\
& $[$ PS (add $=1)]$ & 0.057 & 0.000 & 0.111 & 0.280 \\
\hline \multirow{2}{*}{ PH } & $[$ PS (add $=0)]$ & 0.100 & 0.345 & 0.388 & 0.240 \\
& $[$ PS (add $=1)]$ & 0.094 & 0.341 & 0.385 & 0.233 \\
\hline \multirow{2}{*}{ DF } & $[$ PS (add $=0)]$ & 0.437 & 0.426 & 0.883 & 0.394 \\
& $[$ PS (add $=1)]$ & 0.435 & 0.424 & 0.890 & 0.391 \\
\hline
\end{tabular}

†The standard values equal to check means $(\overline{\mathrm{C}})$, being $3,401.17 \mathrm{~kg} \mathrm{ha}^{-1}$, $103.11 \mathrm{~cm}$ and 76.76 days, for GY, PH and DF, respectively.

An association between the average trait value of a cycle (Figure 2) and the estimated PS (Table 6) was observed for the three traits, i.e., cycles with more favorable average values of a given trait expressed greater potential to generate superior inbred lines as the magnitude of genetic variability among $\mathrm{S}_{0: 2}$ progenies did not narrow across the cycles. Similar results were found in other studies with rice (Santos et al., 2002). These researchers, however, did not apply the method of Jinks and Pooni (1976) in populations under recurrent selection, so that the results of these studies could not be compared with the estimates of the present study.

Superior populations have higher average and desired genetic variability for a given trait. However, in certain cases, a negative association exists between high average values and genetic variability, i.e., high average values coincide with low genetic variance (Santos et al., 2002). In this case, predictive methods, such as that of Jinks and Pooni (1976), are very useful for identifying the most promising populations that can generate the genotypes desired.

The genetic potential of the CNA6 population for generating superior inbred lines increased for the traits GY and $\mathrm{PH}$, after four cycles of recurrent selection (Table 6). Higher estimates of PS in the last cycle may be an indication that progressive population improvement was efficient, as genetic variability was maintained and as the 
average values of these traits improved during selection. Although no genetic gain was observed for DF, the genetic potential for this trait was nearly constant in the population during the first and last selection cycles (Table 6).

The contrasts in PS between cycles in the CNA6 population were alternately positive and negative; however, the magnitude and direction of the changes were not constant during the recurrent selection cycles for any of the traits (Table 6). This reinforces the importance of efficiency in the selection of the $\mathrm{S}_{0.2}$ progenies for recombination and the need to simultaneously consider all traits of interest to the program during selection. Indeed, during this process, important alleles can be lost, which precludes significant and equivalent genetic gains for all traits considered in the selection. This hypothesis may explain the reduced genetic gains in $\mathrm{PH}$ and $\mathrm{DF}$ and the gains in GY, as the selection intensity applied for a given trait and between traits changes with cycles.

The results of this study confirm the success of the recurrent selection method for obtaining genetic gains for quantitative traits in autogamous species. After three cycles of recurrent selection, Breseghello et al. (2009) and Rangel et al. (2002) reported average genetic gains per cycle of $3.6 \%$ and $4.6 \%$ for grain yield, respectively, in upland and lowland rice, using $\mathrm{S}_{0: 2}$ progenies. In soybean, Rose et al. (1992) observed that the average genetic gain per cycle was $5.4 \%$ for grain yield of $\mathrm{S}_{0: 2}$ progenies, after five cycles of recurrent selection. In oats, Holland et al. (2000) obtained average genetic gain of $2.6 \%$ during three cycles of recurrent selection for grain yield of $\mathrm{S}_{0: 1}$ progenies. Niu et al. (2010) evaluated $S_{0: 1}$ progenies of wheat in two cycles of recurrent selection and observed that the average genetic gain per cycle was $2.4 \%$ for grain yield. Silva et al. (2010) reported the average genetic gain per cycle of $3.3 \%$ for grain yield of $\mathrm{S}_{0.2}$ progenies of common bean, after eight cycles of recurrent selection. Therefore, several studies allowed for inferring that the use of recurrent selection method in autogamous crops enables continuous population improvement through progressive cycles, resulting in new superior populations.

These results were achieved because each cycle of recurrent selection resulted in increased frequency of favorable alleles of the quantitative trait under selection and progressive population improvement. However, care must be taken for the genetic variability not to be eroded, mainly through knowledge of the effective size $(\mathrm{Ne})$ of the unit of recombination to use adequate sample sizes, so that amplitude is maintained to allow for improvement by selection and recombination in subsequent cycles.

In this study, genetic progress in grain yield and plant height was achieved after four cycles of recurrent selection of the CNA6 population of upland rice, conducted over a period of 17 years. Selection cycles effectively increased the genetic potential of the population to generate superior inbred lines for grain yield and height plant while maintaining the genetic potential for days-to-flowering.

\section{Acknowledgements}

The authors would like to thank the entire rice breeding team of Embrapa, especially the research assistants and field workers who performed the field trials and collected the data used in our study. We also wish to thank the supporting agency, Coordination for the Improvement of Higher Level Personnel (CAPES), for granting a scholarship to the first author.

\section{References}

Abreu, A.F.B.; Ramalho, M.A.P.; Santos, J.B. 2002. Prediction of seed-yield potential of common bean populations. Genetics and Molecular Biology 25: 323-327.

Berilli, A.P.C.G.; Pereira, M.G.; Trindade, R.D.S.; Costa, F.R.D.; Cunha, K.S.D. 2013. Response to the selection in the 11th cycle of reciprocal recurrent selection among full-sib families of maize. Acta Scientiarum, Agronomy 35: 435-441.

Breseghello, F.; Morais, O.P.; Rangel, P.H.N. 1998. A new method to estimate genetic gain in annual crops. Genetics and Molecular Biology 21: 551-555.

Breseghello, F.; Morais, O.P.; Castro, E.M.; Prabhu, S.A.; Bassinello, P.Z.; Pereira, J.P.; Utumi, M.M.; Ferreira, M.E.; Soares, A.A. 2009. Recurrent selection resulted in rapid genetic gain for upland rice in Brazil. International Rice Research Notes 34: 1-4.

Breseghello, F.; Morais, O.P.; Pinheiro, P.V.; Silva, A.C.S.; Castro, E.M.; Guimarães, E.P.; Castro, A.P.; Pereira, J.A.; Lopes, A.M.; Utumid, M.M.; Oliveira, J.P. 2011. Results of 25 years of upland rice breeding in Brazil. Crop Science 51: 914-923.

Cockerham, C.C. 1963. Estimation of genetic variances. p. 53-94. In: Hanson, W.D.; Robinson, H.F., eds. Statistical genetics and plant breeding. National Academy of Science, Washington, DC, USA.

Cockerham, C.C. 1983. Covariances of relatives from selffertilization. Crop Science 23: 1177-1180.

Colombari Filho, J.M.; Resende, M.D.V.; Morais, O.P.; Castro, A.P.; Guimarães, E.P.; Pereira, J.A.; Utumi, M.M.; Breseghello, F. 2013. Upland rice breeding in Brazil: a simultaneous genotypic evaluation of stability, adaptability and grain yield. Euphytica 192: 117-129.

Duarte, J.B.; Vencovsky, R.; Dias, C.T.S. 2001. Estimators of variance components in the augmented block design with new treatments of one or more populations. Pesquisa Agropecuária Brasileira 36: 1155-1167 (in Portuguese, with abstract in English).

Federer, W.T. 1956. Augmented (or hoonuiaku) designs. Hawaiian Planter's Record 55: 191-208.

Fujimaki, H. 1979. Recurrent selection by using genetic male sterility for rice improvement. Japan Agricultural Research Quarterly 13: 153-156.

Hallauer, A.R.; Miranda Filho, J.B.; Carena, M.J. 2010. Quantitative Genetics in Maize Breeding. Iowa State University, Ames, IA, USA.

Henderson, C.R.; Kempthorne, O.; Searle, S.R.; Krosigk, C. von. 1959. The estimation of environmental and genetic trends from records subject to culling. Biometrics 15: 192-218. 
Holland, J.B.; Bjørnstad, Å.; Frey, K.J.; Gullord, M.; Wesenberg, D.M.; Buraas, T. 2000. Recurrent selection in oat for adaptation to diverse environments. Euphytica 113: 195-205.

Jinks, J.L.; Pooni, H.S. 1976. Predicting the properties of recombinant inbreed lines derived by single seed descent. Heredity 36: 243-266.

Morais, O.P. 2005. Genetic mean and variability in recurrent selection. p. 19-35. In: Guimarães, E.P., ed. Population improvement: a way of exploiting the rice genetic resources of Latin America. Food and Agriculture Organization, Rome, Italy.

Niu, N.; Arief, V.N.; Delacy, I.H.; Lush, D.; Sheppard, J.; Zhang, G.; Dieters, M.J. 2010. Genetic gain in yield and protein over two cycles of a wheat recurrent selection program. Breeding Science 60: 181-186.

Pereira, J.A.; Morais, O.P.; Breseghello, F. 2008. Analysis of heterosis in crosses between varieties of red rice. Pesquisa Agropecuária Brasileira 43: 1135-1142 (in Portuguese, with abstract in English).

Pinheiro, B.S.; Castro, E.M.; Guimarães, C.M. 2006. Sustainability and profitability of aerobic rice production in Brazil. Field Crops Research 97: 34-42.

Rangel, P.H.N.; Morais, O.P.; Zimmermann, F.J.P. 2002. Grain yield gains in three recurrent selection cycles in the CNAIRAT 4 irrigated rice population. Crop Breeding and applied Biotechnology 2: 369-374.

Rangel, P.H.N.; Brondani, C.; Morais, O.P.; Schiocchet, M.A.; Borba, T.C.O.; Rangel, P.N.; Brondani, R.P.V.; Yokoyama, S.; Bacha, R.E.; Ishiy, T. 2007. Establishment of the irrigated rice cultivar SCSBRS Tio Taka by recurrent selection. Crop Breeding and Applied Biotechnology 7: 103-110.

Rose, J.L.; Butler, D.G.; Ryley, M.J. 1992. Yield improvement in soybeans using recurrent selection. Australian Journal of Agricultural Research 43: 135-144.

Santos, P.G.; Soares, A.A.; Ramalho, M.A.P. 2002. Performance of upland rice families selected from segregant populations. Crop Breeding and Applied Biotechnology 2: 237-246.

Searle, S.R. 1971. Linear Models. John Wiley, New York, NY, USA.
Searle, S.R.; Casella, G.; McCulloch, C.E. 1992. Variance Components. John Wiley, New York, NY, USA.

Singh, R.J.; Ikehashi, H.I. 1981. Monogenic male-sterility in rice: introduction, identification and inheritance. Crop Science 21: 286-289.

Silva, G.S.; Ramalho, M.A.P.; Abreu, A.F.B.; Nunes, J.A.R. 2010. Estimation of genetic progress after eight cycles of recurrent selection for common bean grain yield. Crop Breeding and Applied Biotechnology 10: 351-356.

Smith, O.; Hallauer, A.; Russell, W. 1981. Use of index selection in recurrent selection programs in maize. Euphytica 30: 611-618.

Snape, J.W. 1982. Predicting the frequencies of transgressive segregants for yield and yield components in wheat. Theoretical and Applied Genetics 62: 127-134.

Soares, A.A.; Santos, P.G.; Morais, O.P.; Soares, P.C.; Reis, M.D.S.; Souza, M.A. 1999. Genetic progress obtained by upland rice breeding in twenty one years of research in the state of Minas Gerais, Brazil. Pesquisa Agropecuária Brasileira 34: 415-424 (in Portuguese, with abstract in English).

Souza, M.A.; Morais, O.P.; Herán, R.E.C.; Cargnin, A.; Pimentel, A.J.B. 2007. Genetic progress in improving upland rice in the period 1950-2001. Pesquisa Agropecuária Brasileira 42: 371376 (in Portuguese, with abstract in English).

Steel, R.G.D.; Torrie, J.L. 1960. Principles and Procedures of Statistics. McGraw-Hill, New York, NY, USA.

Toledo, J.F.F.; Miranda Filho, J.B. 1985. Prediction of open pollinating populations for the production of superior hybrids. Theoretical and Applied Genetics 71: 563-569.

Toledo, J.F.F. 1987. Predicting the inbreeding and the outcrossing potential of soybean (Glycine max L.) varieties. Brazilian Journal of Genetics 10: 543-558.

Triller, C.; Toledo, J.F.F. 1996. Using the $\mathrm{F}_{3}$ generation for predicting the breeding potential of soybean crosses. Brazilian Journal of Genetics 19: 289-294.

Uphoff, M.D.; Fehr, W.R.; Cianzio, S.R. 1997. Genetic gain for soybean seed yield by three recurrent selection methods. Crop Science 37: 1155-1158. 